\title{
Trademark and patent applications are structurally near-identical and cointegrated: Implications for studies in innovation
}

How to cite (APA): Daizadeh, I. (2021). Trademark and patent applications are structurally near-identical and cointegrated: Implications for studies in innovation. Iberoamerican Journal of Science Measurement and Communication; 1(2), 1-16.

https://doi.org/10.47909/ijsmc.33

Received date: 18 December 2020

Accepted date: 10 March 2021

Handling editor: Ulf Sandström

Copyright: (C) 2021 Daizadeh. This is an open access article distributed under the terms of the CC BY-NC 4.0 license which permits copying and redistributing the material in any medium or format, adapting, transforming and building upon the material as long as the license terms are followed.

Iraj Daizadeh 1

\section{ABSTRACT}

Objective. This paper seeks to test the existence of a "long-run" equilibrium (LRE) dynamic between trademarks and patents, as it would suggest that similar exogenous pressures concomitantly drive these metrics. The restraint in the divergence of the two indices supports an important aspect of the Innovation Agenda, a normative intellectual property (IP)-centric model of the firm, whereby the corporate strategy of science and technology firms is defined by constructing and communicating IP.

Design/Methodology/Approach. Empirical analysis using descriptive statistics, wavelet, cointegration, and structural break analysis is applied to monthly US trademark and patent applications from 1977-2016 to test the potential for LRE.

Results/Discussion. This work finds that the indices have similar (identical) structural attributes (including distribution characteristics, seasonal variation, and short-term cross-periodicity) and are cointegrated (I(1)). Further, structural breakpoints were (near) simultaneous (Trademarks: 1987, 1993, 1999, 2005, 2011; Patents: 1988, 1994, 2000, and 2011). A discussion of potential triggers causing these breaks and the concept of equilibrium in the context of these proxy measures is presented.

Conclusions. From the study, likely, US trademark and patent applications are intimately linked; thus, increasing the likelihood that the Innovation Agenda may correctly capture at least one aspect of the firm. As a corollary, this work further supports the inclusion of trademark analysis in innovation studies. The limitations of the approach including study design are presented.

Originality/Value. To the author's knowledge, the existence of an LRE of trademarks and patents in the framework of the Innovation Agenda is a novel contribution.

Keywords: Trademarks; patents; innovation; cointegration; structural breakpoints; innovation agenda

1 Takeda Pharmaceuticals, United States (Email: iraj.daizadeh@takeda.com; ORCID: 0000-0003-3648-023X) 


\section{INTRODUCTION}

One of the more common methods for inquiring about the dynamics (e.g., rates, structure) of innovativeness in Science and Technology (S\&T) firms is via intellectual property (IP)-related metrics (Dziallas \& Blind, 2018). Simplistically, the rationale of using IP-related proxy measures of innovation primarily rests on the nature of the output (viz., inventions) generated by such firms (Daizadeh et al., 2002). Notably, sponsors may seek one or more patents to protect an invention, assuming such IP meets certain evidentiary standards of utility, novelty, and non-obviousness and perceived future economic rents justify a patent over that of publishing or retaining the knowledge as a trade-secret (ibid). Therefore, one can understand the intrinsic concept captured in a patent, and that the greater number of such IP assets implies greater innovativeness. Optimizing IP generation (and thus innovativeness) has resulted in S\&T firms reorienting their organizations, systems, and processes accordingly (Daizadeh, 2003; 2007).

Conceptually, it is more challenging to extend the logic of innovativeness to other forms of IP, especially to that of trademark-related metrics (e.g., filings) of S\&T firms, as the criteria for meriting a trademark is a more amorphous entity, generally defined as 'word, phrase, symbol, and/or design that identifies and distinguishes the source of the goods of one party from those of other' ${ }^{1}$. Some researchers have expressed significant concern over the use of trademarks of S\&T firms. For example, Hipp and Grupp (2005) state "even services containing no, or only low levels of innovation can be brand protected. This limits the trademarks statistics' value as an innovation indicator" (ibid, p. 526). Others have been more nuanced with their criticism of the approach, considering the topic as one of definition (Flikkema et al., 2015), and are leveraging relatively recent research viewing the link between trademarks and innovation accordingly. For exhaustive accounts on the literature on such topics, readers are referred to Dziallas and Blind (2019), Siekierski et al. (2018), among others.

In the past, among other interesting metrics, Daizadeh $(2007,2009)$ found strong (>96\%; p-value < 0.0001) correlation between patent applications (Patents) and trademarks filings (Trademarks) over a multi-year (1970-2002) period. In the same work, Daizadeh also proposed that the corporate strategy of S\&T firms follow a normative model, termed the 'Innovation Agenda' (see Figure 1), which was conjectured from the legal and financial nature of patents, trademarks, publications, and press releases, may help in understanding the identified correlative patterns. The Innovation Agenda, as proposed, is to be comprised of several socio-economic S\&T firm-specific metrics including US Research and Development Spend, Number of Trademark Filings and Registrations, Number of Patent Applications and Issuances, Number of Press Releases, and various S\&T related Stock Indices. While the data used (as is here) is US-specific, it may be generalizable to any intellectual-property based entrepreneurial S\&T intensive jurisdiction. In that work, Daizadeh found - using annual values for these metrics and based on correlation and partial-correlation analysis - a series of interesting findings including correlation and partial correlation across these selected metrics.

Lastly, the use of Trademark data in innovation studies has been of recent interest. Daizadeh (2007, 2009) added empirical support for the conjecture that if Patents were a proxy measure of innovation, and if Trademarks were strongly correlated with Patents, then Trademarks may also play a role as a proxy measure of innovation. As can be observed in the Innovation Agenda (Figure 1), the S\&T firm considers Trademarks similar to that of Patents; these two indices are presumed to evolve concomitantly. Of key interest is the role in IP communication, which requires further consideration in future work. Recently there has been renewed interest in the use of Trademarks (and related data) as measures of innovation (see Dziallis \& Blind, 
2019). Characterizing the interrelatedness between these metrics beyond that of correlation may further strengthen the argument that Trademarks be a standard measure of innovativeness in S\&T firms. By interrelatedness, it is meant that there is a reciprocal relationship of one to the other, as shown in Figure 1.

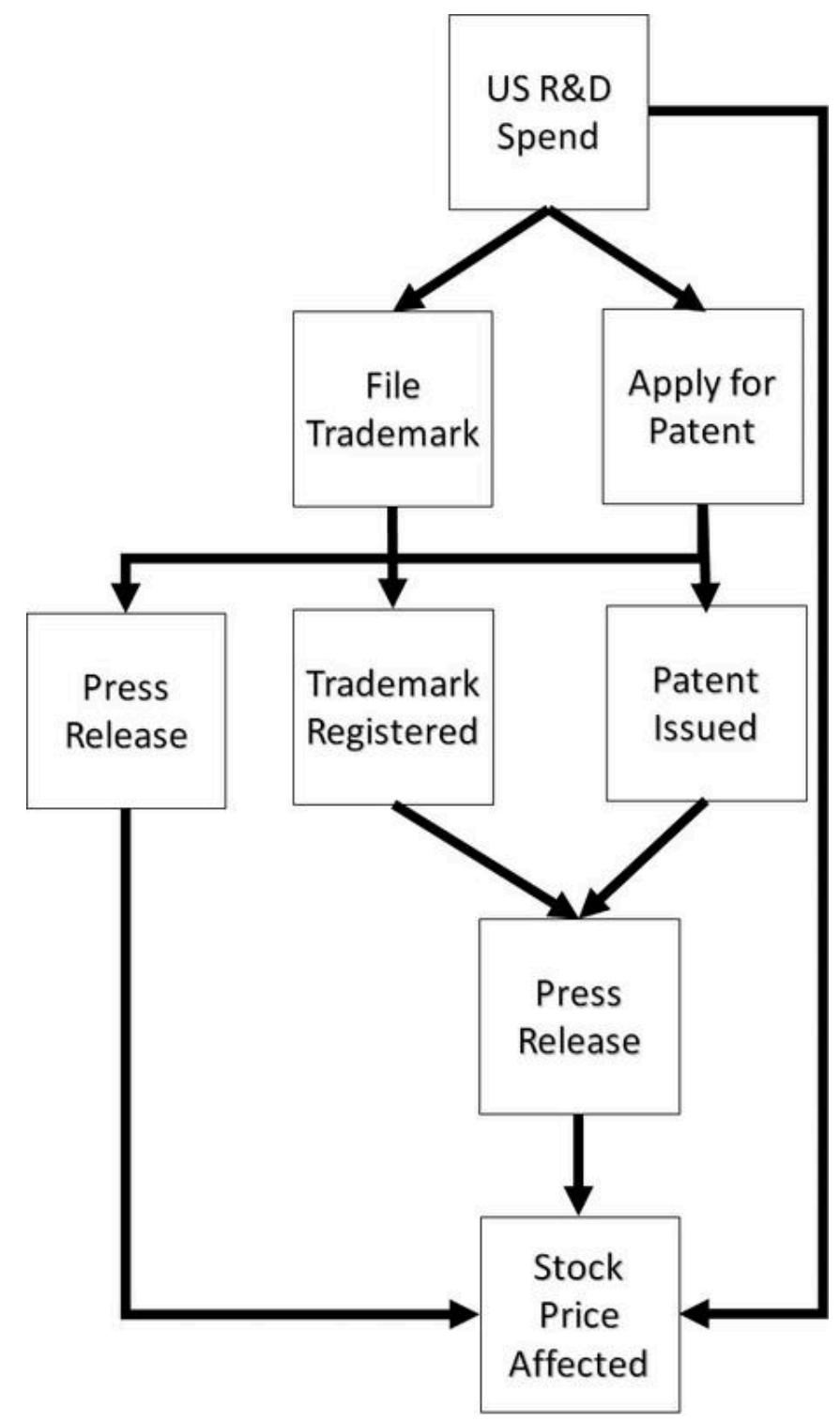

Figure 1. The innovation agenda, as defined by Daizadeh (2009).

Time-series statistical analysis is prevalent across scientific disciplines and includes a diverse assortment of approaches. Statistical practices of relevance to this paper, as we seek to understand the temporal co-mobility (interrelatedness) of Patents and Trademarks (bivariates), include descriptive statistics (e.g., seasonal variation), cointegration, structural break/change point, and cross-wavelet analyses. While several approaches may have been taken to investigate the interrelatedness of a bivariate system, the methods described below were selected due to several factors including ease of access, ease of interpretation, the prevalence of use (and thus greater confidence in strength and limitations of methods), and intrinsic criteria of data (e.g., non-normality). 
Various descriptive statistics were performed to provide insight into the distribution (e.g., normality) and stability (e.g., stationarity), and to better select further statistical analyses. As previously mentioned, Daizadeh $(2007,2009)$ found a strong correlation between Patents and Trademarks. Using time-series decomposition and cross-wavelet analyses, as a qualitative tool, the nature of the correlation (synchronicity) was further explored including elucidating periodicity contributing the most to the correlation pattern. This work empirically explores monthly observations over roughly 40 years for both time series. Generally, this report finds that Trademarks and Patents (time series) are similar statistical moments (mean, variance, skew, and kurtosis), non-normal and non-stationary with seasonal variation, with short-term periodicity, across all years explored. A cross-wavelet analysis was also performed to obtain a view into latent periodicity. The analysis reconfirmed the high correlation but resolved interesting dynamics in short-term periodicity associated with the most recent decade.

Cointegration (unlike correlation) analysis captures so-called 'long-run equilibrium' derived from stochastic relationships restricting co-movement divergence between the time series under-study (Granger, 1981; Engle \& Granger, 1987; Dolado et al., 1999). That is, cointegration regards the degree of differences in the time-series as opposed to the directionality of the co-movement (e.g., positive correlation in which the bivariates move in the same direction). The cointegration statistical analyses, included those of the Johansen and Philips and Ouliaris tests, confirmed that the time series were co-moving, implying that some exogenous effect(s) were imposing a constraint on this system.

As with other statistics, cointegration may be affected by a non-trivial change in the course of the time series, which may be termed a 'structural break,' 'structural change,', or a 'regime shift'. While there are several definitions for a structural break, and thus methods to elucidate or predict such changes, the following is illustrative: "Structural break as an unpredictable event in which the relationship among the variables in a model changes, and this change cannot be predicted in any sense from past data" (Maheu \& Gordon, 2008). Should such abrupt changes occur (quasi)-simultaneously, then it may be presumed that the same exogenous event affects both Trademarks and Patents, adding further (if not confirmatory) evidence of not only interrelatedness between the variables. Here, it is found from generalized fluctuation tests that structural breaks exist and identify and date the breakpoints as Trademarks: 1987, 1993, 1999, 2005, 2011; Patents: 1988, 1994, 2000, and 2011, using standard models (see below for details and associated citations). A discussion of potential triggers for these dates is presented below.

In this paper, assuming the Innovation Agenda model for the IP-intensive S\&T firm, the study hypothesis explored is that if Patents and Trademarks are both affected by the same and/or similar exogenous variables, then their respective time series should be 'interrelated.' Further, these data add support to an assumption proposed in the Innovation Agenda; namely, that an exogenous factor(s) was applied to patent applications and trademark filings, leading to the interrelationship. Bivariate interrelatedness is explored empirically using descriptive statistics, structural breakpoint, and cointegration analyses on the bivariate monthly time series over an extended period (1977-2016; see Methodology) compared with the original Daizadeh paper.

Observation of simultaneous/quasi-simultaneous structural changes, the existence of cointegration (which would imply a 'long term equilibrium' restraining the differences between the time series), and other structural co-movements (such as synchronicity, coherence) in the bivariate time series would support the theory that common (or similar) exogenous factors exist, and thus further add additional supportive evidence to DIA theory (necessary for formalizing further study), as well as illustrates the import of trademarks to the innovation process and thus to S\&T firms generally (see Results). This manuscript concludes with 
a discussion of the assumptions and limitations of the approach, and avenues for future development.

\section{METHODOLOGY}

This objective of the methodology seeks to test the existence of a "long-run" equilibrium (LRE) dynamic between trademark and patent applications as described in Figure 1. The existence of such an LRE would strongly suggest that similar exogenous pressures concomitantly drive these metrics, restraining them from evolving disparately. The approach taken in the methodology is to use orthogonal statistical tests to perform the investigation on time series representation of the two indices of interest - trademark and patent applications. First, a descriptive statistical analysis is performed to better understand the dynamics of the time series studied. This analysis includes seeking seasonal effects. A cointegration study is then conducted to investigate if there is a long-term correlation effect. Then a structural break analysis is performed. The structural break analysis is performed to test for abrupt changes in the statistical features of the time series; comparing the results between the two-time series would suggest that factors affecting one would also affect the other if the breaks were temporally coincident. As these tests are technical, and a description is beyond the scope of this manuscript, readers are directed to the represented citations. The data sources and statistical methods used to achieve this objective are described in depth below.

\section{Data sources and preparation}

The data were comprised of the monthly number of US patent applications (Patents) and the monthly number of US trademark filings (Trademarks) from 1977 to 2016. The data on Patents and Trademarks were obtained from the respective publicly available websites supported by the United States Patent and Trademark Office (USPTO) as described below.

- Patents:

- Search criteria: Application Filing Date: "APD/MM/\$/YYYY" located on http://patft.uspto.gov/netahtml/PTO/search-adv.htm

- Trademarks:

- Search criteria Filing Date: "(YYYYMM\$)[FD]" located on http://tmsearch.uspto.gov/bin/ gate.exe?f=tess\&state=4804:57thz4.1.1

Two searches were manually executed, resulting in 472 data points for each variable and captured in Excel for import into R. The 472 data points for each variable represents monthly observations throughout the study (approximately 40 years). The data is presented in the Supplementary Materials section of the manuscript for ease of reference and the sake of reproducibility.

\section{Statistical analysis}

The methodology followed standard implementation, and default parameters were used throughout. The general algorithm for the analysis is as follows:

- Load bivariate time series, identify and replace outliers with an average of prior and posterior-month values (R package 'tsoutliers' (López-de-Lacalle, 2019). Note: 3 outliers were determined for Trademarks (September 1982; November 1989; and June 1999) and 
4 for Patents (September 1982, June 1995, October 2007, and March 2013).

- Decompose data and perform descriptive statistics, including deriving kurtosis, skew $(R$ package 'moments' (Komsta and Novomestky, 2015)), nonparametric (Spearman and Kendall) correlation coefficients (ibid), and cross-wavelet analyses (R Package 'biwavelet,' (Gouhier et al., 2019)) on full-time series.

- Test for structural breakpoints (SBPs) using empirical fluctuation processes (R package 'strucchange' (Zeileis et al., 2002; 2003)):

- Ordinary least squares-cumulative sums and moving sums (OLS-CUSUM, MOSUM)) and recursive (REC) CUSUM and REC-MOSUM (see p. 4/5 of Zeileis et al, 2002).

- Significance testing (see p. 9 of ibid)

- Date SBPs and define segments:

- Bai-Perron breakpoint method (Bai and Perron, 2003; R package 'strucchange' (see Zeileis et al., 2002, 2003; see p. 112/113 in Zeileis et al., 2003). A segment is defined as the longest length of time between two SBPs (either Patents or Trademarks).

- Test for cointegration using Johansen Procedure and Phillips and Ouliaris (Pz) tests (R package 'ucra' (Pfaff, 2008)) for full-time series and segments.

- Determine the order of integration using Kwiatkowski-Phillips-Schmidt-Shin (KPSS), Augmented Dickey-Fuller (ADF), and the Phillips and Peron tests (R package 'forecast' (Hyndman et al., 2019; Hyndman \& Khandakar, 2008) for full-time series and segments.

\section{RESULTS}

\section{Descriptive statistics}

The distributions of the two-time series were similar (e.g., approximately symmetric (skew) and platykurtic) and thus no transformation was performed on the data (Table 1). The respective trends of the time series generally evolve in time in an 'exponential manner,' both have similar per-annum quarterly seasonal effects, with increased contributions from the stochastic (random) elements post-2010, with a spike at circa 2000 and circa 1995 for Trademarks and Patents, respectively (Figures 2 and 3). Qualitatively it would that Trademarks present a somewhat greater degree of 'randomness' than Patents.

\begin{tabular}{lllllllllll}
\hline Variable & \multirow{2}{*}{ Minimum } & $\begin{array}{l}\text { 1st } \\
\text { Quartile }\end{array}$ & \multicolumn{1}{c}{ Median } & Mean & $\begin{array}{l}\text { 3rd } \\
\text { Quartile }\end{array}$ & Maximum & $\begin{array}{l}\text { Standard } \\
\text { deviation }\end{array}$ & Skewness Kurtosis \\
\hline Trademarks & 1895 & 5537 & 15456 & 15276 & 23574 & 37317 & 9418.054 & 0.202 & 1.76 \\
Patents & 3134 & 7598 & 14468 & 13930 & 19422 & 30969 & 6523.347 & 0.185 & 1.76 \\
\hline
\end{tabular}

Table 1. Descriptive statistics of trademarks and patents. 


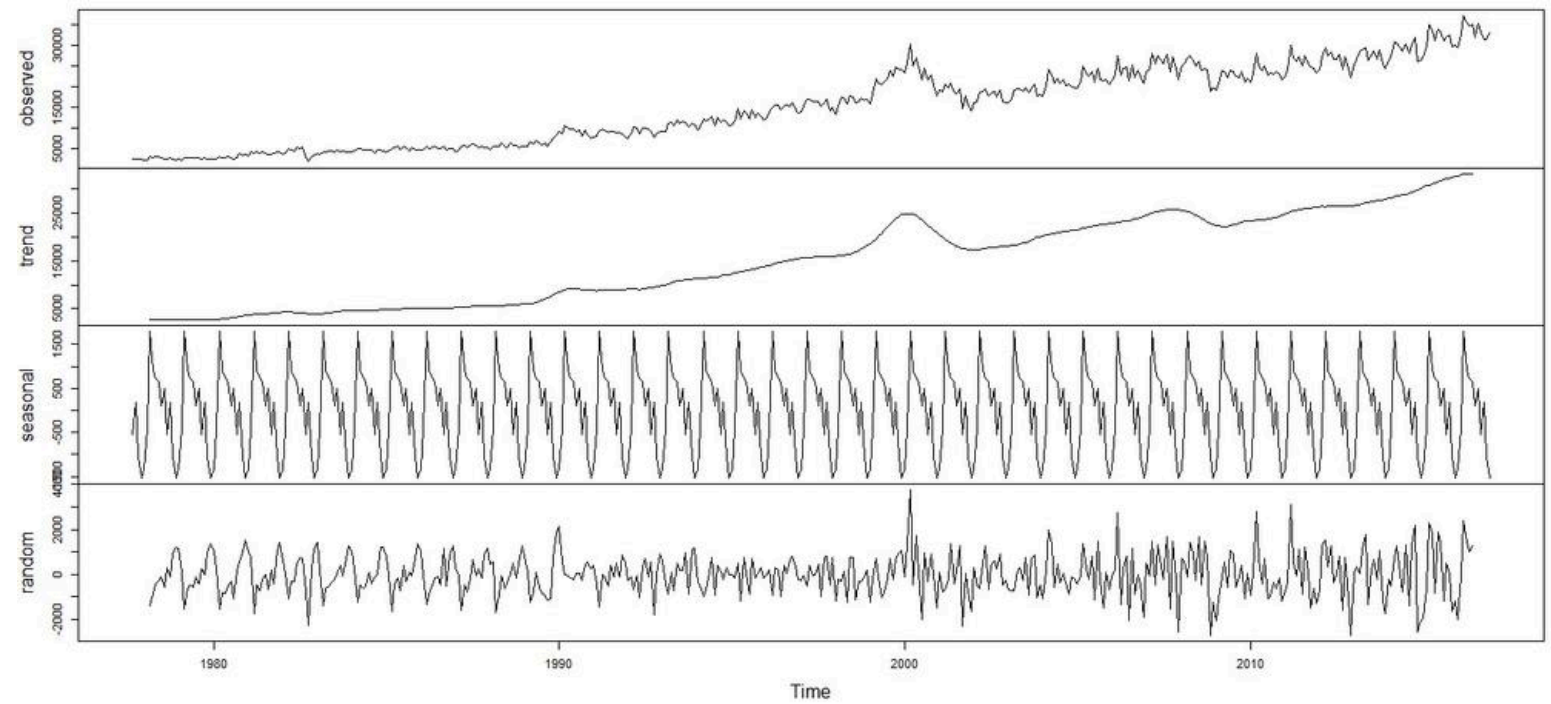

Figure 2. Time series decomposition of trademarks.

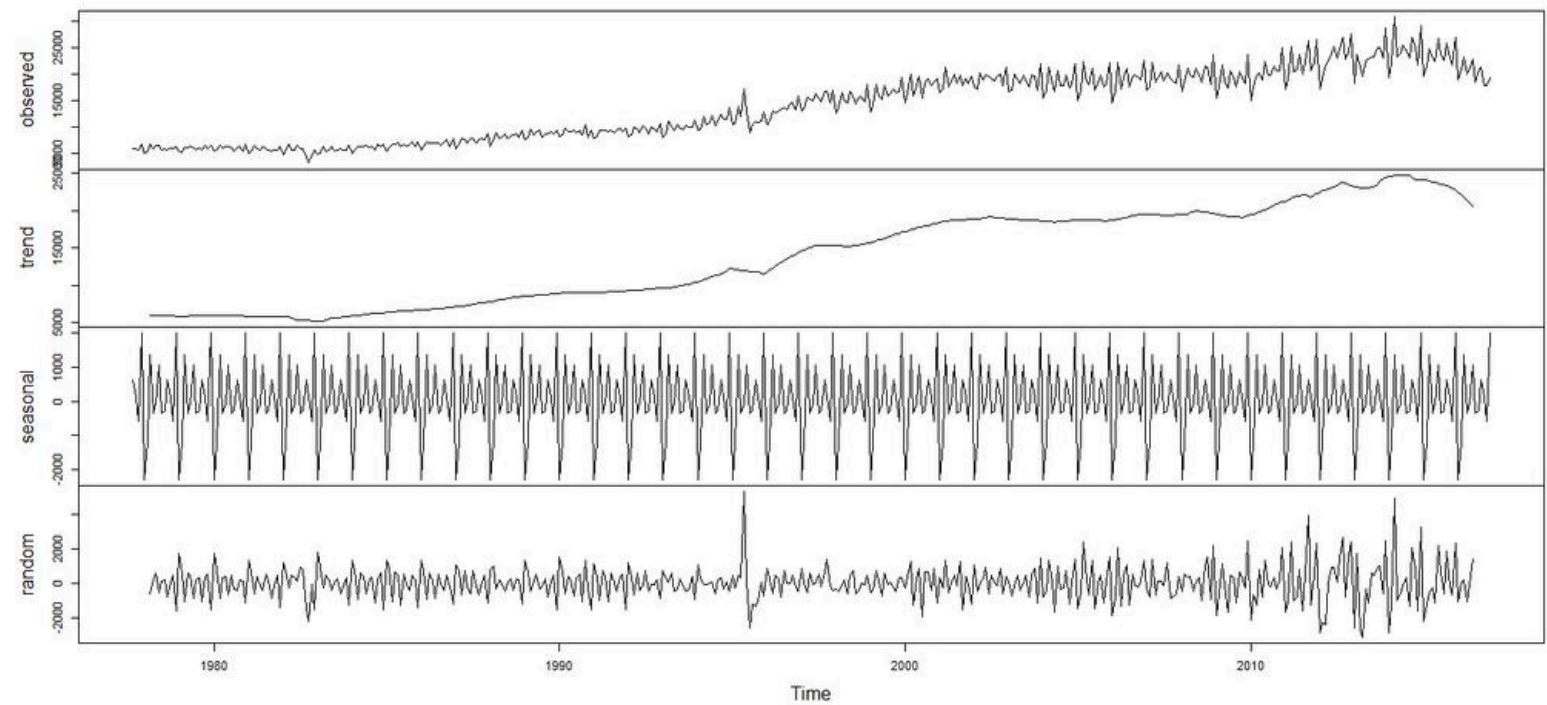

Figure 3. Time series decomposition of patents.

\section{Correlation and cross-wavelet analysis}

Spearman and Kendall's analysis finds a strong coefficient of correlation of 0.94 and 0.80 , respectively, between Trademarks and Patents; this reconfirms the work of Daizadeh (2007, 2009) for an extended period (1977-2016). Further examination using cross-wavelet analysis shows broadly high to very high (1) coherency (red to dark-red splotches) across the Trademark/Patent spectra and periods. Relatively low periods post-1995 and more uniformly post-2002 demonstrate increased bivariate synchronicity (at $5 \%$ statistical significance) (Figure 4). 


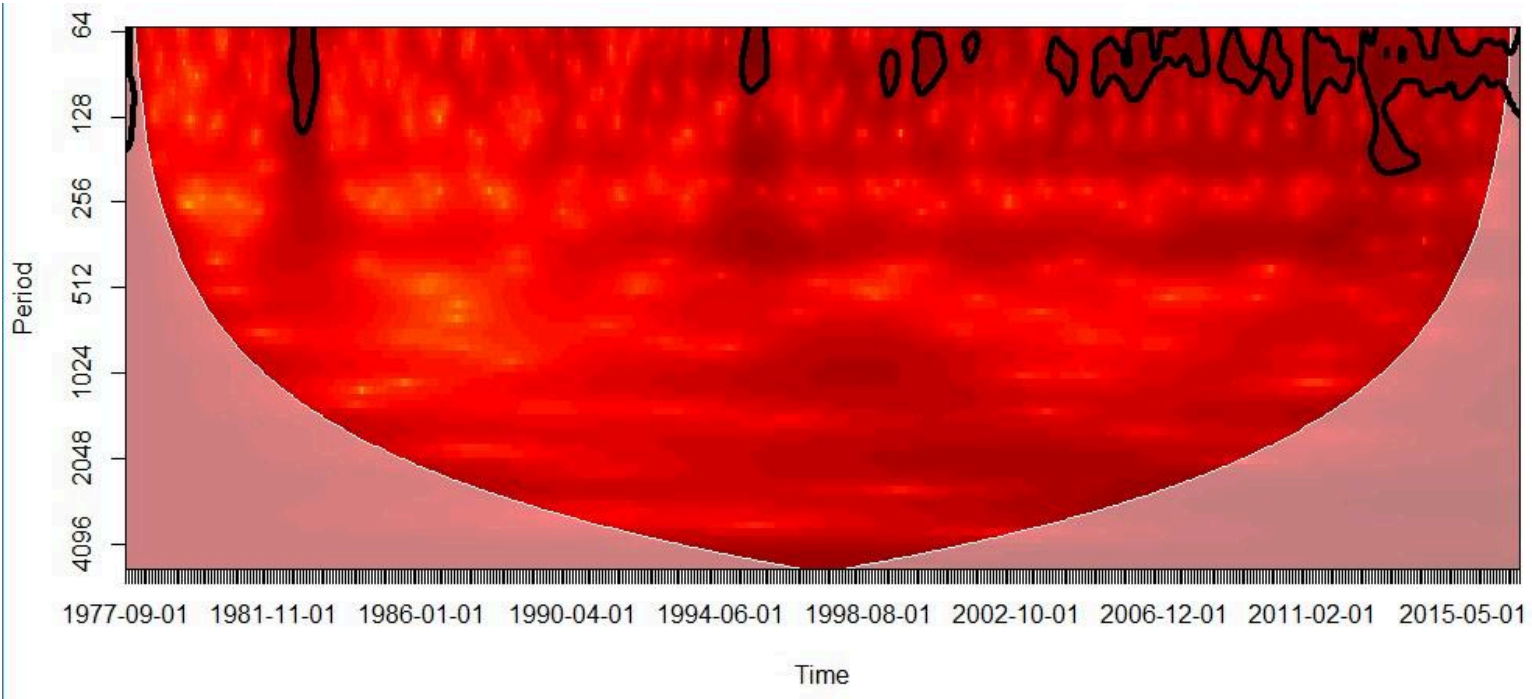

Figure 4. Cross-wavelet analysis of trademarks and patents; solid black contour lines designate the 5\% significance.

\section{Existence, testing, and dating of structural breakpoints, and subsequent segmenting of the time series}

The empirical fluctuation processes (EFPs) (ordinary least squares (OLS) and recursive modeling (REC)) test the null hypothesis of "no structural change' [which] should be rejected when the fluctuation of the empirical processes gets improbably large compared to the fluctuation of the limiting process" (Zeileis et al., 2002, p. 6). The EFPs were executed with a significance criterion (alpha) of $5 \%$. The results of these four tests for Trademarks are presented in Figure 5; a similar result was found for all tests for Patents (figure not shown). Significance testing for the existence of SBPs is presented in Table 2, with p-values less than or equal to 0.01 .

As can be seen in either of Figures 5 and Table 2, the EFPs cross the critical value boundary and therefore rejecting the null hypothesis of no SBP at the $5 \%$ level. Further, the complex structures for both (Approvals and Guidances) time series across the tests suggest multiple structural breakpoints (Zeileis et al., 2005). 

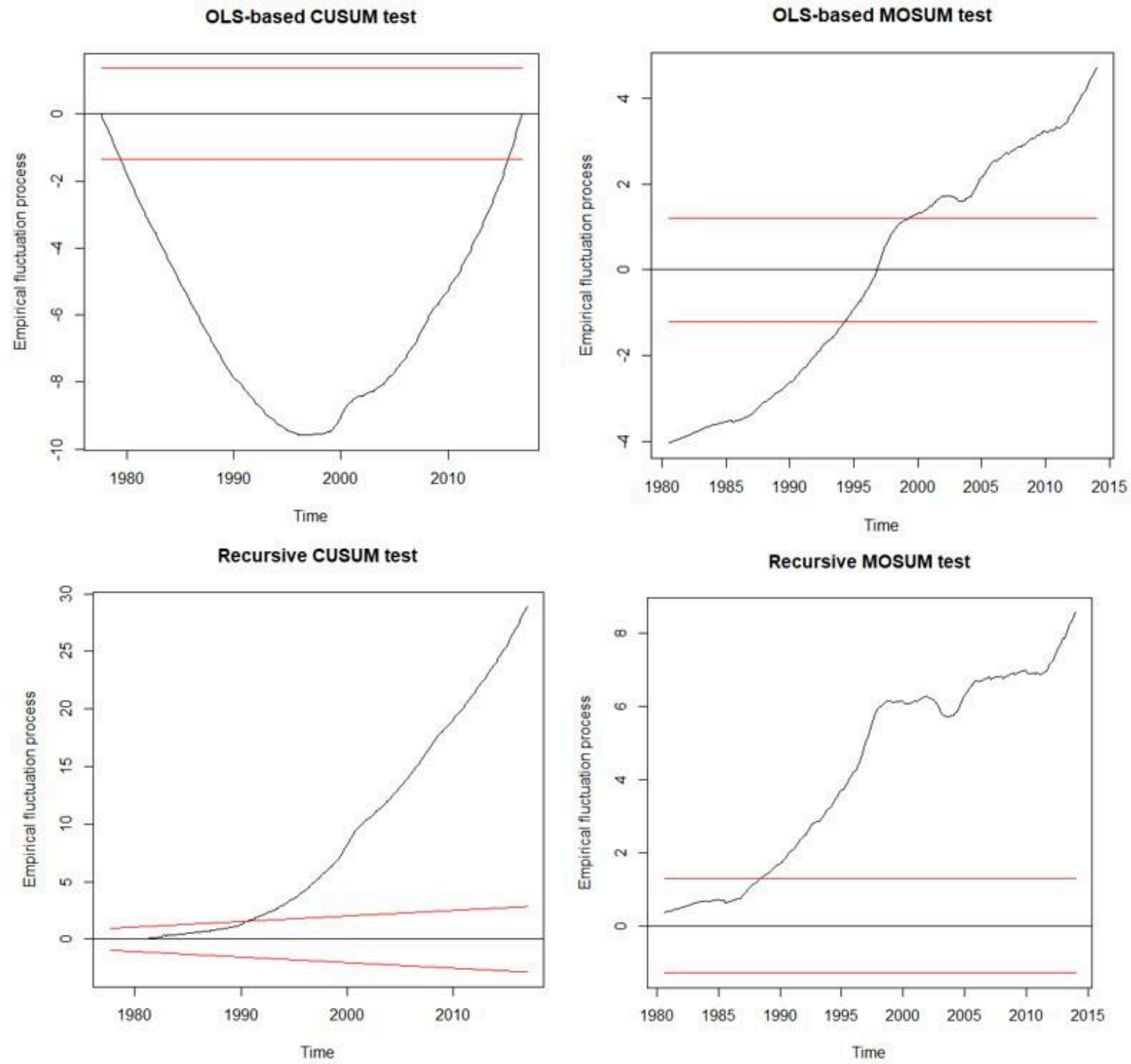

Figure 5. Existence of structural breakpoints for trademarks.

\begin{tabular}{lllll}
\hline Variable & OLS-CUSUM & OLS-MOSUM & REC-CUSUM & REC-MOSUM \\
\hline Trademarks & $<2.2 \mathrm{e}-16$ & 0.01 & $<2.2 \mathrm{e}-16$ & 0.01 \\
Patents & $<2.2 \mathrm{e}-16$ & 0.01 & $<2.2 \mathrm{e}-16$ & 0.01
\end{tabular}

Table 2. Significance testing ( $p$-value) for the existence of structural breakpoints in trademarks and patents.

\section{Dating of structural breakpoints}

The general idea of the Bai-Perron dynamic programming algorithm to date the structural breakpoints is to elucidate the breakpoints through minimizing the residual sum of squares of a linear regression model (additional details may be found in Bai \& Perron, 2003; and Zeileis et al., 2003). SBPs (including confidence limits) are presented in Figure 6 and Table 3. 


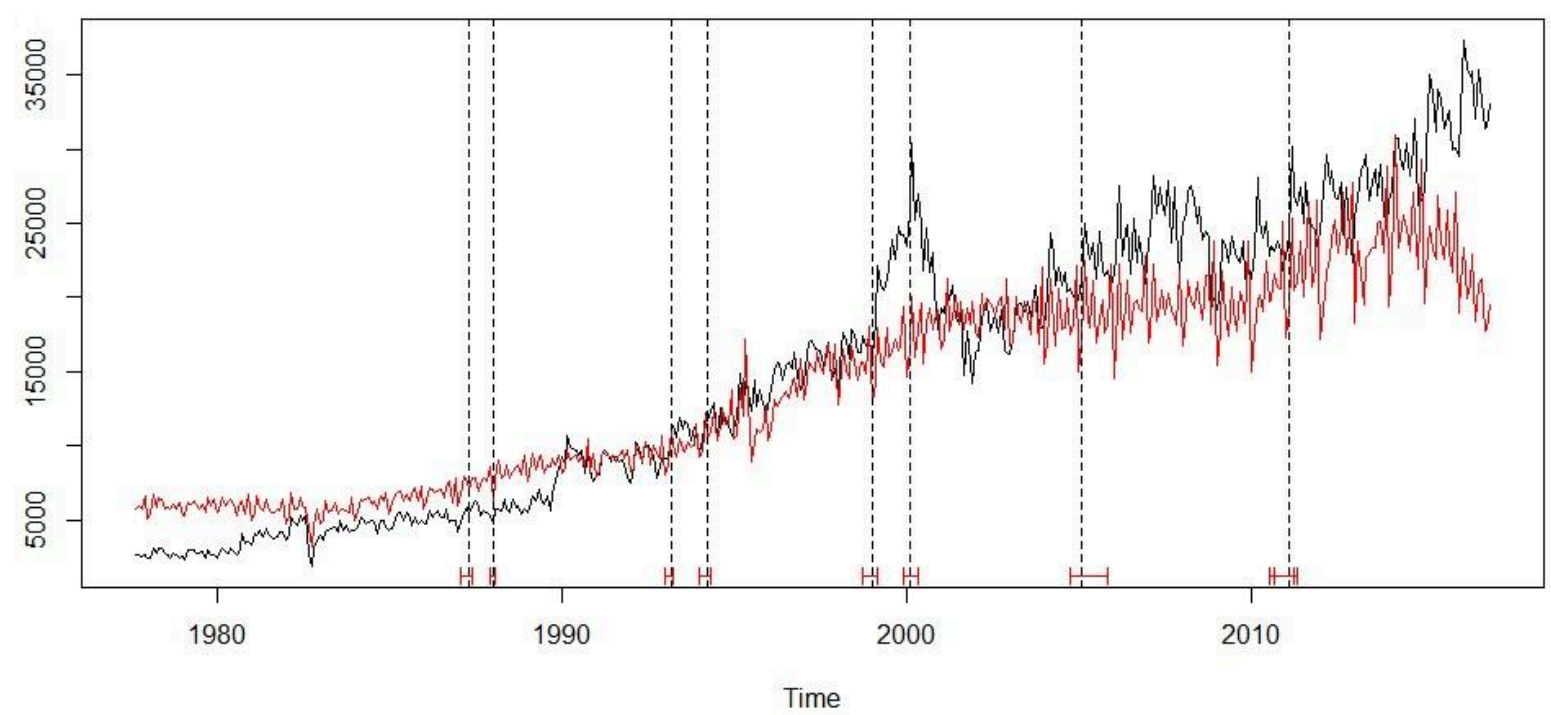

Figure 6. Structural breakpoints with corresponding confidence intervals (see Table 3) identified in trademarks (black) and patents (red).

\begin{tabular}{|c|c|c|c|c|c|}
\hline \multicolumn{3}{|c|}{ Trademarks } & \multicolumn{3}{|c|}{ Patents } \\
\hline $2.7 \%$ & Breakpoint & $97.5 \%$ & $2.7 \%$ & Breakpoint & $97.5 \%$ \\
\hline Feb 1987 & May 1987 & Jul 1987 & Jan 1988 & Feb 1988 & Apr 1998 \\
\hline Jan 1993 & Mar 1993 & Apr 1993 & Dec 1993 & Apr 1994 & May 1994 \\
\hline Oct 1998 & Jan 1999 & Mar 1999 & Dec 1999 & Feb 2000 & Jul 2000 \\
\hline Oct 2004 & Feb 2005 & Nov 2005 & & & \\
\hline Sept 2010 & Feb 2011 & Apr 2011 & Apr 2010 & Feb 2011 & Apr 2011 \\
\hline
\end{tabular}

Table 3. Dating (via Bai-Perron) of the structural breakpoints in trademarks and patents.

The data suggests several segments in which there are no abrupt changes in the intrinsic variability of the time series (stationarity). Thus, several time segments of stationarity were elucidated and afford ease in further analyses given minimal statistical variance/fluctuations. The existence of stationarity during these periods strongly suggests the lack of strength of any exogenous factor (e.g., the promulgation of novel legal frameworks and/or technologies) on the time-course of these variables. Thus, the heuristic was defined to be the longest time between Trademarks and Patents structural breakpoints (Table 4); 6 such time-segments were identified and used for the rest of the analysis.

\begin{tabular}{cr}
\hline Segment & Heuristic: The longest time between Trademarks and \\
\hline 1 & Sep 1977 to April 1987 \\
2 & Feb 1988 to Feb 1993 \\
3 & May 1994 to Dec 1998 \\
4 & Mar 2000 to Jan 2005
\end{tabular}




\begin{tabular}{|c|c|}
\hline Segment & Heuristic: The longest time between Trademarks and Patents structural breakpoints* \\
\hline 5 & Mar 2005 to Jan 2011 \\
\hline 6 & Mar 2011 to Dec 2016 \\
\hline \multicolumn{2}{|c|}{${ }^{*}$ That is, the origin to the month before breakpoint: October 1983} \\
\hline
\end{tabular}

\section{Cointegration and the maximum order of integration (I(d))}

Results for the Johansen Procedure and Phillips and Ouliaris tests demonstrated cointegration at alpha $</=1 \%$ for the full bivariate time series and the third-, fifth-, and sixth-time segments. The size of the test statistic is notable for both tests across the full time series (Table 5).

\begin{tabular}{|c|c|c|c|}
\hline \multirow[t]{2}{*}{ Segment } & \multicolumn{2}{|c|}{$\begin{array}{l}\text { Johansen procedure } \\
\text { (trace statistics, without linear trend and constant) }\end{array}$} & \multirow{2}{*}{$\begin{array}{l}\text { Phillips and Ouliaris Test } \\
\begin{array}{l}\text { Value of Test Statistic versus (v) } \\
\text { critical value of the test (at the } \\
\text { lowest level of alpha) }\end{array}\end{array}$} \\
\hline & $\begin{array}{l}r<=1 \text { : Test statistic versus }(v) \\
\text { critical value of the test (at the } \\
\text { lowest level of alpha) }\end{array}$ & $\begin{array}{l}r=0 \text { Test statistic versus }(v) \\
\text { critical value of the test (at the } \\
\text { lowest level of alpha) }\end{array}$ & \\
\hline $\begin{array}{l}\text { Full-time } \\
\text { series }\end{array}$ & & 75.47 v $24.60(1 \%)$ & 222.6575 v $55.1911(1 \%)$ \\
\hline 1 & & 23.37 v $19.96(5 \%)$ & \\
\hline 2 & & 36.34 v $24.60(1 \%)$ & \\
\hline 3 & & 24.64 v $24.60(1 \%)$ & 51.1519 v $40.8217(5 \%)$ \\
\hline 4 & 9.95 v $9.24(5 \%)$ & 74.61 v $24.60(1 \%)$ & \\
\hline 5 & 11.58 v $9.24(5 \%)$ & 83.56 v $24.60(1 \%)$ & 83.8507 v $55.1911(1 \%)$ \\
\hline 6 & & 33.83 v $24.60(1 \%)$ & 54.1304 v $40.8217(5 \%)$ \\
\hline
\end{tabular}

Table 5. Results of cointegration tests across full bivariate time series and each time-segment.

Maximum order of integration $(\mathrm{I}(\mathrm{d}))$ - that is, the number of differences required to bring a given time series into stationarity - of the full time series was determined to be I(1), given that it is the maximum of 0 or 1 with or without considering structural breakpoints (that is, per segment) (Table 6).

\begin{tabular}{lllll}
\hline Variable & Segment & KPSS & ADF & PP \\
\hline Trademarks & Full dataset & 1 & 1 & 1 \\
Patents & 1 & 1 & 1 & 1 \\
Patents & 2 & 1 & 1 & 1 \\
Trademarks & 1 & 0 & 0 \\
Patents & & 1 & 1 & 1 \\
Trademarks & & 1 & 0 & 0
\end{tabular}




\begin{tabular}{lllll}
\hline Variable & Segment & KPSS & ADF & PP \\
\hline Patents & 3 & 1 & 1 & 1 \\
Trademarks & 4 & 1 & 1 & 0 \\
Patents & 5 & 1 & 0 & 0 \\
Trademarks & & 0 & 0 & 0 \\
Patents & 6 & 0 & 0 & 0 \\
Trademarks & & 0 & 0 & 0 \\
Patents & 1 & 1 & 1 \\
Trademarks & 0 & 0 & 0 \\
\hline
\end{tabular}

Table 6. Number of differences required to bring the time series into stationarity.

\section{DISCUSSION AND CONCLUSIONS}

The Daizadeh Innovation Agenda (DIA) offers a formal normative scaffold to explore variables of interest to innovation on the company, sector, industry, or national basis for science and technology firms with a specific focus on securing economic rents from specific forms of IP (notably, patents and trademarks) and their communication and subsequent monetization (Daizadeh, 2007; 2009; 2006; 2007b). While inquiries into the DIA model were restricted to only broad correlation analysis and a specific case study, additional work is needed to further validate the model. Importantly, this additional work may also provide insights into metrics investigating innovative productivities of firms.

Specifically, the DIA model suggests an interrelationship (that is, a mutual or reciprocal recognition) between various metrics. Here, the interrelationship between trademark filings (Trademarks) and patent applications (Patents) is explored using a set of statistical analyses that seek to empirically identify structural similarities between the temporal evolution of Trademarks and Patents. The descriptive analysis demonstrated that the distributions of the time series are similar. Correlation and cross-wavelet analysis clearly showed synchronicity and coherence between the time series. Cointegration analysis demonstrates a 'long-run' equilibrium (restricting divergence) has been established between the time series. The DIA model proposes that R\&D expenditure is a driver in patent and trademark originations. This is consistent with the time series (cointegration) analysis performed by Verbeek and Debackere (2006). These authors find "patent evolution is strongly related to (...) levels of public and private R\&D expenditure..." (see abstract and conclusions in ibid).

With regards to the dating of structural breakpoints in the bivariate time series, while additional statistical work is required to better understand sensitivity (as different approaches may realize different dates), it is challenging to link economic shocks that may have caused the abrupt concomitant temporal perturbations to the dates of simultaneous / near-simultaneous shocks in the bivariate time series (viz., 1988, 1993/1994, 1999/2000, and 2011). For example, one can hypothesize (and therefore test) that domestic economic hardships affecting R\&D (e.g., the dot-com crisis) or the end of a bull market may have been a direct or contributing factor to the abrupt temporal changes in the IP-assets of S\&T firms such as Patents and Trademarks (see Bleoca, 2014). Simultaneously, one can also hypothesize that there was an 'event' associated with the start of the recent "bull market" over 
the last decade that may have been initiated in the early 2010s (potentially irrespective of or in addition to fluctuations in the legal landscape (notably, from a patent perspective, the 'Leahy-Smith America Invents Act' that became law in $\left.2011^{2}\right)$ ). Further work would need to be done to examine such causal factors during the years identified in this work.

Lastly, from a conceptual perspective, the "long-run" equilibrium of R\&D expenditure spill-over effects such as IP-related assets (Trademarks and Patents) and the equilibrium (stationary) processes elucidated between the structural breakpoints (herein called 'regimes' - see Table 4) may be recast along the lines of Schumpeter's theory of business cycles and more generally innovation theory. From this work, while there may be abrupt discontinuations (assumed to be due to non-endogenous / exogenous factors) within short periods (approximately $<2$ years), overall economic and innovative progress (as defined by several metrics including those of intellectual property) has continued during the relatively long-time course under-study (monthly intervals of over 40 years). The approach taken herein treats Trademarks and Patents as macro-socio-economic variables averaging across degrees (e.g., radical versus incremental), types (e.g., process versus product), and sectors (e.g., biotech versus manufacturing) of innovativeness. Aligned with Schumpeterian thought around business cycles, and in terms of cointegration of certain macro-socio-economic variables, Konstantakis and Michaelides (2017, p. 20) note that "it is exactly upon the existence of this equilibrium relationship that Schumpeterian business cycles were founded since progressive evolution of innovative activity expressed through technology, leads to the evolution of economic activity as a whole".

As with any statistical analysis, there are advantages and disadvantages as well as practical aspects (e.g., computational intensity or algorithm complexity) of the methodologies used within the constraints of the data collected (Daizadeh, 2020). Thus, multiple, complementary, and orthogonal methods to investigate the interrelationship were used. For example, wavelet analysis is well-known to be of utility across a broad range of implementations (e.g., cross-wavelet) with non-stationary time series (Rhif et al., 2019) well complemented both the decomposition (notably seasonal effects) results and the correlation coefficient calculations; two different cointegration tests were performed: Johansen trace test (Johansen, 1988) and Phillips and Ouliaris test (Phillips \& Ouliaris, 1990).

The analysis presented in this paper provides supportive evidence for a component of the DIA model as well as metrics tracking innovativeness, however, many further inquiries remain. Future experiments may include:

- Geography: e.g., ex-US versus US interrelationship inquiries

- Additional trademark and patent variables: e.g., granted patents and designated trademarks

- Integration of additional DIA variables: e.g., numbers of press releases over time and financial metrics

- Deepened analysis: Mapping identified structural breakpoints to the introduction of the promulgation of new/updated legal frameworks and/or new technologies to better understand the impact.

In conclusion, a strong and intimate interrelationship exists between Trademarks and Patents. Beyond supporting the DIA model, this work thus adds to the emerging literature (beginning in part with Daizadeh, 2007) that Trademarks should be of interest as an 
innovation metric as a unique entity and/or in combination with other such metrics.

\section{Conflicts of Interest Statement}

The author declares that there is no conflict of interest.

\section{Statement of Data Consent}

The data generated during the development of this study has been included in the manuscript.

\section{Disclosures and Disclaimers}

The author is an employee of Takeda Pharmaceuticals; however, this work was completed independently of his employment. The views expressed in this article may not represent those of Takeda Pharmaceuticals.

\section{Notes}

${ }^{1}$ https://www.uspto.gov/trademarks-getting-started/trademark-basics/

trademark-patent-or-copyright

${ }^{2}$ https://www.govinfo.gov/app/details/PLAW-112publ29

\section{REFERENCES}

Bai, J., \& Perron, P. (2003). Computation and analysis of multiple structural change models. Journal of applied econometrics, 18(1), 1-22. https://doi.org/10.1002/jae.659

Bleoca, L. (2014). Knowledge management, innovation, and intellectual capital corporate value in the United States. Journal of Business and Economics, 5(9), 1614-1636.

Daizadeh, I., Miller, D., Glowalla, A., Leamer, M., Nandi, R., \& Numark, C. I. (2002). A general approach for determining when to patent, publish, or protect information as a trade secret. nature biotechnology, 20(10), 1053-1054. https://doi.org/10.1038/nbt1002-1053

Daizadeh, I. (2003). Integrating intellectual property within the organizational social structure. nature biotechnology, 21(5), 573-575. https://doi.org/10.1038/nbt0503-573

Daizadeh, I. (2006). Using intellectual property to map the organisational evolution of firms: Tracing a biotechnology company from startup to bureaucracy to a multidivisional firm. Journal of Commercial Biotechnology, 13(1), 28-36. https://doi.org/10.1057/ palgrave.jcb.3050032

Daizadeh, I. (2007a). Intellectual property management in R\&D intensive firms. International Journal of Intellectual Property Management, 1(3), 184-205. https://doi.org/10.1504/ IJIPM.2007.013554

Daizadeh, I. (2007b). 'Patent journalism': An emergence of a new form of science communication. World Patent Information, 30(3), 244-247. https://doi.org/10.1016/ j.wpi.2007.10.005 
Daizadeh, I. (2007c). Issued US patents, patent-related global academic and media publications, and the US market indices are inter-correlated, with varying growth patterns. Scientometrics, 73(1), 29-36. https://doi.org/10.1007/s11192-007-1749-1

Daizadeh, I. (2009). An intellectual property-based corporate strategy: An R\&D spend, patent, trademark, media communication, and market price innovation agenda. Scientometrics, 80(3), 731-746. https://doi.org/10.1007/s11192-008-2105-9

Daizadeh, I. (2020). Investigating rates of food and drug administration approvals and guidances in drug development: a structural breakpoint/cointegration timeseries analysis. Therapeutic innovation \& regulatory science,54(5), 1056-1067. https://doi.org/ $10.1007 / \mathrm{s} 43441-020-00123-5$

Daizadeh, I. (2020). Trademark filings and patent application count time series are structurally near-identical and cointegrated: Implications for studies in innovation. arXiv preprint arXiv:2012.10400. Retrieved from https://arxiv.org/pdf/2012.10400

Doladoa, J.J.; Gonzalo, J.; \& Marmol, F. (1999). A Primer in Cointegration. Retrieved from http://www.eco.uc3m.es/ jgonzalo/cointegration.pdf

Dziallas, M., \& Blind, K. (2019). Innovation indicators throughout the innovation process: An extensive literature analysis. Technovation, 80, 3-29. https://doi.org/10.1016/ j.technovation.2018.05.005

Engle, R.F.; \& Granger, C.W.J. (1987). Co-integration and error correction: Representation, estimation and testing. Econometrica, 55, 251-76.

Flikkema, M.; Castaldi, C.; De Man, A-P.; \& Seip, M. (2015). Explaining the trademark-innovation linkage: The role of patents and trademark filing strategies. Paper presented at DRUID15, Rome, June 15-17 2015. Retrieved from https://conference.druid.dk/ acc_papers/nv9r3f3sl6p5e0431rj6sxfblv4g.pdf

Granger, C.W.J. (1981). Some properties of time series data and their use in econometric model specification. Journal of Econometrics, 16(1), 121-130. https://doi.org/10.1016/ 0304-4076(81)90079-8

Gouhier, T.C.; Grinsted, A.; \& Simko, V. (2019). R package biwavelet: Conduct Univariate and Bivariate Wavelet Analyses (Version 0.20.19). Retrieved from https://github.com/tgouhier/ biwavelet

Hipp, C.; \& Grupp, H. (2005). Innovation in the service sector: The demand for service-specific innovation measurement concepts and typologies. Research Policy, 34(4), 517-535. https://doi.org/10.1016/j.respol.2005.03.002

Hyndman, R.; Athanasopoulos, G.; Bergmeir, C.; Caceres, G.; Chhay L; O'Hara-Wild, M.; Petropoulos, F.; Razbash, S.; Wang, E.; \& Yasmeen, F. (2019). Forecast: Forecasting functions for time series and linear models. R package version 8.8. Retrieved from http://pkg.robjhyndman.com/forecast

Hyndman R.J.; \& Khandakar, Y. (2008). Automatic time series forecasting: the forecast package for R. Journal of Statistical Software, 27(3), 1-22. http://dx.doi.org/10.18637/ jss.v027.i03 
Johansen, S. (1988). Statistical analysis of cointegration vectors. Journal of economic dynamics and control, 12(2-3), 231-254. https://doi.org/10.1016/0165-1889(88)90041-3

Konstantakis, K. N., \& Michaelides, P. G. (2017). Does technology cause business cycles in the USA? A Schumpeter-inspired approach. Structural Change and Economic Dynamics, 43, 15-26. https://doi.org/10.1016/j.strueco.2017.05.005

Komsta, L.;\& Novomestky, F. (2015). moments: Moments, cumulants, skewness, kurtosis and related tests. $\mathrm{R}$ package version 0.14 . Retrieved from https://CRAN.R-project.org/ package $=$ moments

López-de-Lacalle, J. (2019). tsoutliers: Detection of Outliers in Time Series. R package version 0.6-8. Retrieved from https://CRAN.R-project.org/package=tsoutliers

Maheu, J.; \& Gordon, S. (2008). Learning, forecasting and structural breaks. Journal of Applied Econometrics, 23(5), 553-583. https://doi.org/10.1002/jae.1018

Pfaff, B. (2008). Analysis of Integrated and Cointegrated Time Series with R (2nd Edition). New York, USA: Springer.

R Core Team. (2019). R: A language and environment for statistical computing. R Foundation for Statistical Computing, Vienna, Austria (v. 3.6.1). Retrieved from https://www.R-project.org/

Phillips, P. C. B.; \& Ouliaris, S. (1990). Asymptotic Properties of Residual Based Tests for Cointegration. Econometrica, 58, 165-193. https://doi.org/10.2307/2938339

Rhif, M., Ben Abbes, A., Farah, I. R., Martínez, B., \& Sang, Y. (2019). Wavelet transform application for/in non-stationary time-series analysis: a review. Applied Sciences, 9(7), 1345. https://doi.org/10.3390/app9071345

Santoni, G.J. (1987). The great bull markets 1924-29 and 1982-87: Speculative bubbles or economic fundamentals. Federal Reserve Bank of St. Louis. Retrieved from https://pdfs.semanticscholar.org/ba2e/46724cbdc30372a8294bafab4985cf0988f8.pdf

Siekierski, P., Lima, M., Borini, F., \& Pereira, R. (2018). International academic mobility and innovation: a literature review. Journal of Global Mobility, 6(3/4), 285-298. https://doi.org/ 10.1108/JGM-04-2018-0019

Trapletti, A.; \& Hornik, K. (2019). tseries: Time Series Analysis and Computational Finance. $\mathrm{R}$ package version $0.10-47$.

Verbeek, A., \& Debackere, K. (2006). Patent evolution in relation to public/private R\&D investment and corporate profitability: Evidence from the United States. Scientometrics, 66, 279-294. https://doi.org/10.1007/s11192-006-0021-4

Zeileis, A.; Leisch, F.; Hornik, F.; Kleiber, C. (2002). strucchange: An R Package for Testing for Structural Change in Linear Regression Models. Journal of Statistical Software, 7(2), 1-38. http://dx.doi.org/10.18637/jss.v007.i02

Zeileis, A., Kleiber, C., Krämer, W., \& Hornik, K. (2003). Testing and dating of structural changes in practice. Computational Statistics \& Data Analysis, 44(1-2), 109-123. https://doi.org/10.1016/S0167-9473(03)00030-6 